\title{
Pengaruh Stres Kerja Dan Kepuasan Kerja Terhadap Kinerja Karyawan
}

\author{
Hartono Jessie Steven dan Arif Partono Prasetio \\ Universitas Telkom Bandung \\ Email: hartonojesse11@gmail.com dan partono67@gmail.com \\ Diterima: November 2019; Dipublikasikan Januari 2020
}

\begin{abstract}
ABSTRAK
Penelitian ini bertujuan untuk mengetahui pengaruh tingkat stres kerja, tingkat kepuasan kerja terhadap tingkat kinerja karyawan pada perusahaan Telkom Witel Jakarta Utara. Metode pengumpulan data penelitian diperoleh dengan cara penyebaran kuesioner terhadap karyawan Telkom Witel Jakarta Utara sebanyak 190 responden. Kuesioner yang digunakan dalam penelitian ini memiliki 46 butir pernyataan dengan skala likert 6 poin. Metode sampling yang digunakan pada penelitian ini adalah nonprobability sampling dengan teknik sampling jenuh. Teknik analisis data yang digunakan pada penelitian ini yaitu analisis deskriptif dan analisis jalur. Hasil yang diperoleh pada penelitian ini menunjukkan bahwa stres kerja berpengaruh signifikan negatif terhadap kinerja karyawan dan kepuasan kerja berpengaruh signifikan positif terhadap kinerja karyawan Telkom Witel Jakarta Utara.
\end{abstract}

Kata Kunci: stres kerja, kepuasan kerja, kinerja karyawan

\begin{abstract}
This study aims to determine the effect of work stress levels, job satisfaction levels on the level of employee performance in Telkom Witel North Jakarta. The research data collection method was obtained by distributing questionnaires to Telkom Witel North Jakarta employees totaling 190 respondents. The questionnaire used in this study had 46 statements with a 6-point Likert scale. The sampling method used in this study is nonprobability sampling with saturated sampling technique. Data analysis techniques used in this study are descriptive analysis and path analysis. The results obtained in this study indicate that work stress has a significant negative effect on employee performance and job satisfaction has a significant positive effect on the performance of Telkom Witel North Jakarta employees.
\end{abstract}

Keywords: job stress, job satisfaction, employee perfomance 


\section{PENDAHULUAN}

Persaingan dalam dunia bisnis dari masa ke masa semakin ketat. Perubahan lingkungan yang terjadi sebagai penyebab kunci munculnya persaingan bisnis yang semakin sulit untuk diprediksi. Dalam era kompetisi bisnis saat ini, perusahaan yang bertahan hanyalah perusahaan yang memiliki strategi inovasi dan strategi bisnis yang lebih (Millin,2019). Sebuah perusahaan memiliki aset penting yang harus diperhatikan agar tujuan yang telah ditetapkan dapat berjalan sesuai yang diinginkan. Menurut Shafiq dan Hamza (2017) aset utama dalam perusahaan adalah sumber daya manusia. Sumber daya manusia yang mampu memberikan kontribusi dengan baik merupakan sumber daya manusia yang memberi dukungan kepada keberhasilan perusahaan. Malik (2019) memaparkan bahwa sumber daya manusia yang memiliki komitmen dan tanggung jawab yang dapat meningkatkan kinerjanya. Kinerja karyawan merupakan unsur utama dalam membantu perusahaan untuk mencapai sasaran organisasi. Diamantidis dan Chatzoglou (2018) mengungkapkan bahwa kinerja yang dapat dikatakan baik apabila lingkungan kerja dan dukungan manajemen telah optimal.

Terdapat beberapa faktor yang dapat mempengaruhi kinerja karyawan. Menurut Falola et al. (2014) mengungkapkan bahwa pelatihan dan pengembangan adalah alat strategis yang sangat diperlukan untuk meningkatkan kinerja karyawan. Ahli lain memaparkan bahwa kepuasan dari profesi, lingkungan kerja dan kebijakan kompensasi merupakan faktor yang mempengaruhi kinerja karyawan. Selanjutnya Hur et al (2015) bahwa mengelola emosi karyawan adalah salah satu aset terpenting bagi sebagian besar organisasi, khususnya organisasi berbasis layanan karena manfaat nyata terhadap kinerja yang sukses.

Stres kerja merupakan beban yang berlebihan yang diberikan perusahaan terhadap karyawannya sehingga karyawan merasa stres dan dapat menurun kinerjanya, sementara kepuasan kerja merupakan faktor utama pada karyawan dalam meningkatkan kinerjanya. Fenomena dari penelitian ini didapat dari hasil preliminary dan data sekunder perusahaan. Oleh karena itu dalam penelitian ini menggunakan stres kerja dan kepuasan kerja sebagai faktor utama yang dapat mempengaruhi kinerja karyawan pada PT Telkom Witel Jakarta Utara.

\section{Stres Kerja}

\section{TINJAUAN PUSTAKA}

Fahmi (2013:256) menyatakan bahwa stres kerja adalah suatu keadaan yang menekan diri dan jiwa seseorang di luar batas kemampuannya, sehingga jika terus dibiarkan tanpa ada solusi maka ini akan berdampak pada kesehatannya. Stres tidak timbul begitu saja namun sebab-sebab stres timbul umumnya diikuti oleh faktor peristiwa yang mempengaruhi kejiwaan seseorang dan peristiwa itu terjadi diluar dari kemampuannya sehingga kondisi tersebut telah menekan jiwanya. Griffin dan Moorhead (2013:181) mendefinisikan stres sebagai respon adaptif seseorang terhadap rangsangan yang menempatkan tuntutan psikologis atau fisik yang berlebihan padanya. Mangkunegara (2013:157) mengungkapkan stres kerja disebabkan karena adanya beban pekerjaan yang dirasakan terlalu berat, tidak adanya pengawasan kerja, waktu kerja yang diberikan cukup padat, lingkungan kerja yang tidak baik, adanya konflik kerja serta adanya perbedaan dalam menilai antara pimpinan dengan karyawan. Dampak stres yang diungkapkan oleh Luthans (2015:295) bahwa stres memiliki dampak paling kuat pada tindakan yang agresif seperti adanya permusuhan, keluhan dari seorang karyawan serta 
adanya tindakan perusahaan yang dilakukan secara berencana ataupun secara sengaja. Adapun alat ukur yang digunakan pada penelitian ini sebagai indikator stres kerja yang digunakan oleh Prasetio et al (2019).

\section{Kepuasan Kerja}

Kepuasan kerja adalah keterlibatan pekerjaan, tingkat dimana orang mengidentifikasi secara psikologis dengan pekerjaan mereka dan menganggap tingkat kinerja yang dianggap penting bagi harga diri mereka untuk mencapai tujuan yang ditetapkan oleh perusahaan (Robbins dan Judge, 2018:50). Menurut Masram dan Muah (2017:117) Kepuasan kerja merupakan respon afektif atau emosional terhadap berbagi segi atau aspek pekerjaan seseorang sehingga kepuasan kerja bukan merupakan konsep tunggal. Seseorang dapat relatif puas dengan salah satu aspek pekerjaan dan tidak puas dengan satu atau lebih aspek lainnya. Edison et al. (2016:216) berpendapat bahwa faktor yang mempengaruhi kepuasan kerja adalah gaji yang didapatkan, pekerjaan itu sendiri, peluang promosi, kondisi pekerjaan, rekan kerja serta keamanan pekerjaan didalam organisasi tersebut. Dampak kepuasan kerja yang diungkapkan oleh Griffin dan Moorhead (2013:74) kepuasan kerja akan berdampak pada pekerjaan menjadi mengurangnya tingkat absensi, memberikan kontribusi positif, dan tetap Bersama organisasi. Penelitian ini menggunakan alat ukur yang digunakan oleh Prasetio et al (2019) untuk mengukur tingkat kepuasan kerja.

\section{Kinerja Karyawan}

Menurut Kasmir (2016:182) kinerja karyawan adalah hasil kerja dan perilaku kerja seseorang dalam suatu periode tertentu. Sementara menurut Fahmi (2013:127) kinerja adalah hasil yang diperoleh oleh suatu organisasi baik organisasi tersebut bersifat profit oriented dan non profit oriented yang dihasilkan selama satu periode waktu. Fattah (2017:24) berpendapat bahwa faktor dalam meningkatkan kinerja adalah kemampuan pribadi, usaha yang dicurahkan dan dukungan organisasi. Kondisi tersebut karyawan dapat berkontribusi dengan baik kepada perusahaan. Menurut Burso (2018:86) penampilan kerja secara kualitas dan kuantitas yang dilakukan oleh karyawan baik secara individu maupun kelompok akan memberikan kontribusi terhadap kenaikan produktivitas dalam organisasi. Dalam penelitian ini menggunakan alat ukur yang digunakan oleh Pradhan dan Jena (2017) untuk mengukur tingkat kinerja karyawan.

\section{Hubungan Stres Kerja Terhadap Kinerja Karyawan}

Terdapat beberapa ahli dari beberapa negarayang menjelaskan hubungan antara stres kerja terhadap kinerja karyawan. Menurut Hanafi et al. (2018) menemukan bahwa ada pengaruh signifikan stres kerja terhadap kinerja karyawan dan kepuasan kerja. Penelitian lain yang dilakukan oleh (Akgunduz, 2015) berpendapat bahwa mempekerjakan karyawan dengan harga diri yang tinggi dan memprioritaskan pengurangan beban yang berlebihan dapat meningkatkan kinerja karyawan. Menurut Rajeshwaran dan Aktharsha (2017) hasil yang ditemukan bahwa stres terkait keluarga, stres terkait bawahan, stres akibat kelelahan dan stres berdasarkan kepribadian ditemukan sebagai prediktor signifikan dari komitmen organisasi dan komitmen berkelanjutan memainkan peran penting dalam kinerja pekerjaan. Penelitian lain yang dilakukan oleh (Khuong dan Yen, 2016) menemukan faktor-faktor kerja memiliki pengaruh signifikan positif terhadap stres kerja dan stres kerja memiliki pengaruh negatif terhadap kinerja pekerjaan karyawan. Sedangkan, Nyangahu dan Bula (2015) temuannya menunjukkan bahwa ada hubungan antara pekerjaan stres secara signifikan positif mempengaruhi kinerja seorang individu. 
H1: Stres kerja memiliki pengaruh signifikan negatif terhadap kinerja karyawan

\section{Hubungan Kepuasan Kerja Terhadap Kinerja Karyawan}

Beragam penelitian dari beberapa negara yang dilakukan para ahli tentang hubungan antara kepuasan kerja dan kinerja karyawan. Penelitian yang dilakukan oleh Dekoulou dan Trivellas (2015) menemukan bahwa operasi yang berorientasi pada pembelajaran adalah prediktor penting dari kepuasan kerja karyawan yang mempengaruhi kinerja karyawan. Menurut Farooqui dan Nagendra (2014) mengatakan bahwa terdapat hubungan antara organisasi orang dengan kepuasan kerja dan kinerja karyawan. Menurut Melian Gonzalez dan Bulchand Gidumal (2014) bahwa kepuasan dengan kepemimpinan senior, kompensasi dan keseimbangan kerja masing masing berdampak pada kinerja karyawan. Sedangkan menurut Valei dan Jiroudi (2016) terdapat hubungan antara kepuasan kerja dan kinerja dalam industri media. Selanjutnya penelitian yang dilakukan oleh Pang dan Lu (2018) bahwa terdapat hubungan antara motivasi dan kepuasan kerja terhadap kinerja dalam konteks pengiriman container.

$\mathrm{H} 2$ : Kepuasan kerja memiliki pengaruh signifikan positif terhadap kinerja karyawan

\section{Hubungan Stres Kerja Terhadap Kepuasan Kerja}

Penelitian terkait stres kerja terhadap kepuasan kerja yang dilakukan oleh (Gosmawi dan Dsilva, 2019) bahwa terdapat hubungan antara stres kerja dan kepuasan kerja terhadap kehidupan karyawan di industri perhotelan dengan menggunakan metode campuran sekuensial. Penelitian lainnya dilakukan oleh Guinot et al. (2014) menemukan bahwa kepercayaan interpersonal berhubungan positif pada kepuasan kerja dan stres kerja. Sedangkan penelitian yang dilakukan oleh Hoboubi et al. (2017) bahwa stres kerja dan kepuasan kerja adalah faktor penting yang mempengaruhi produktivitas tenaga kerja pada industri kimia. Menurut Singh dan Nayak (2015) berdasarkan temuannya bahwa lebih sedikit staf polisi dalam gelombang kejahatan yang tinggi adalah salah satunya alasan utama dibalik stres kerja serta ketidakpuasan kerja di kalangan pejabat polisi H3: Stres kerja memiliki pengaruh signifikan positif terhadap kepuasan kerja

\section{Kerangka Pemikiran}

Pada penelitian ini yang telah dijelaskan dan dipaparkan pada latar belakang adalah bagaimana pengaruh stress kerja dan kepuasan kerja terhadap kinerja karyawan, serta penelitian ini dikuatkan dengan adanya teori-teori yang telah dijelaskan oleh beberapa peneliti terdahulu sehingga dapat menjadi dasar untuk membuat penelitian ini. Kerangka pemikiran pada penelitian ini bertujuan untuk menunjukan bahwa terdapat pengaruh stres kerja dan kepuasan kerja terhadap kinerja karyawan.

Pengukuran stres kerja sebagai variabel bebas dalam penelitian ini, penulis menggunakan pengukuran teori dari Prasetio et al. (2019) dengan indikator tuntutan tugas dan tuntutan pribadi. Kemudian kepuasan kerja sebagai variabel bebas dalam penelitian ini menggunakan indikator sifat pekerjaan, gaji, promosi, pengawasan, dan hubungan antar rekan kerja yang diadopsi dari Robbin dan Judge (Prasetio et al. 2019). Selanjutnya alat ukur kinerja karyawan sebagai variabel terikat pada penelitian ini menggunakan pengukuran teori dari Pradhan dan Jena (2017) dengan indikator menilai kinerja tugas yang diberikan, kinerja adaptive, dan kinerja konsektual. 


\section{Responden}

\section{METODE PENELITIAN}

Penelitian ini dilakukan di PT Telkom Witel Jakarta Utara. Dengan jumlah populasi sebanyak 190 orang dan sampel pada penelitian ini berjumlah 190 orang yang diharapkan mampu mewakili populasi yang ada. Data yang diperoleh melalui kuesioner yang disebarkan kepada 190 karyawan Telkom Witel Jakarta Utara dengan tingkat pengembalian kuesioner sebesar 100\% yaitu sebanyak 190 responden. Detail demografis responden terpapar pada Tabel 1.

Tabel 1:Aspek Demografis

\begin{tabular}{cccc}
\hline Faktor & & & \\
Demografi & Klasifikasi & Jumlah Responden & Persentase \\
& & & \\
\hline Jenis & Pria & 122 & $64 \%$ \\
Kelamin & Wanita & 68 & $36 \%$ \\
& $<25$ & 19 & $10 \%$ \\
& $25-30$ & 25 & $13 \%$ \\
Usia & $>30-35$ & 10 & $5 \%$ \\
& $>35-40$ & 5 & $3 \%$ \\
& $>40-45$ & 24 & $12 \%$ \\
& $>45-50$ & 43 & $23 \%$ \\
Lama & $>50$ & 64 & $34 \%$ \\
Bekerja & $>1$ tahun & 12 & $6 \%$ \\
& $>3$ tahun & 23 & $12 \%$ \\
& $>-5$ tahun & 16 & $15 \%$ \\
Posisi & $>10$ tahun & 28 & $58 \%$ \\
Kerja & Non Jabatan & 111 & $94 \%$ \\
& Supervisor & 102 & $6 \%$ \\
& Manajer & 6 & $0 \%$ \\
\hline Pendidikan & SMA/SMK & 0 & $35 \%$ \\
& Diploma & 67 & $26 \%$ \\
& S1 & 49 & $35 \%$ \\
& S2 & 67 & $4 \%$ \\
\hline
\end{tabular}

Sumber: Data Diolah.

\section{Pengukuran}

Kuesioner dalam mengukur tiga variabel dalam penelitian ini terdiri dari 46 pernyataan yang diantaranya, 8 item pernyataan untuk mengukur variabel (X1) stres kerja dengan menggunakan alat ukur dari Prasetio et al. (2019), 15 item pernyataan untuk mengukur variabel (X2) kepuasan kerja dengan menggunakan alat ukur dari Prasetio et al. (2019) dan 23 pernyataan untuk mengukur variabel (Y) kinerja karyawan dengan menggunakan alat ukur Pradhan dan Jena (2017). Skala dalam penelitian ini terdiri dari 6 skala likert, yaitu 6 (sangat setuju), 5 (setuju), 4 (ragu cenderung setuju), 3 (ragu cenderung tidak setuju), 2 (tidak setuju), 1 (sangat tidak setuju). Pada penelitian ini menggunakan uji reliabilitas dengan menggunakan Cronbach's Alpha dengan nilai yang dihasilkan sebesar 0,785 untuk variabel (X1) stres kerja, sedangkan untuk variabel (X2) kepuasan kerja nilai pada Cronbach's Alpha dihasilkan sebesar 0,749 dan untuk variabel (Y) kinerja karyawan nilai Cronbach's Alpha sebesar 0,751. Dalam proses pengolahan 
data penulis menggunakan IBM SPSS 20. penelitian ini menguji pengaruh variabel stres kerja dan kepuasan kerja sebagai variabel independent terhadap kinerja karyawan sebagai variabel dependent.

\section{Teknik Analisis}

Teknik analisis data yang digunakan dalam penelitian ini menggunakan teknik deskriptif dan kausal. Deskriptif merupakan analisis yang menggambarkan dari karakteristik data tersebut, sedangkan analisis kausal merupakan kaitan dengan studi tentang satu atau lebih variabel mempengaruhi perubahan dalam variabel lain. Adapun analisis jalur juga menjadi dasar dalam pemaparan hubungan langsung dan tidak langsung (Riduwan dan Kuncoro, 2017).

\section{HASIL DAN PEMBAHASAN}

Sebelum melakukan analisis jalur, terdapat beberapa langkah yang harus dilakukan terlebih dahulu yaitu uji asumsi klasik yang terdiri dari uji normalitas, uji multikolinieritas, dan uji heteroskedastisitas. Hasil yang diperoleh dari uji asumsi klasik yang dilakukan pertama adalah uji normalitas dan diperoleh nilai sebesar 0,572 yang artinya data memiliki distribusi normal. Uji asumsi klasik berikutnya adalah uji multikolineritas dan diperoleh nilai VIF 1,021 dan Tolerance 0,979 maka diasumsikan tidak ada multikolinearitas. Uji asumsi klasik yang terakhir adalah uji heteroskedastisitas dan diperoleh nilai stres kerja 0,447 dan kepuasan kerja 0,173 hal tersebut dapat disimpulkan bahwa regresi tidak terjadi masalah heteroskedastisitas.

Dalam Tabel 2 terdapat hasil untuk melihat seberapa kontribusi variabel independen terhadap variabel dependen dibahas dalam penelitian ini. $\mathrm{R}^{2}$ diperoleh sebesar .283 atau 28,3\%, hal tersebut menunjukkan bahwa presentase stres kerja dan kepuasan kerja sebesar 28,3\% atau dapat dikatakan kontribusi dari variabel independen sebesar $28,3 \%$. Sedangkan $71 \%$ dipengaruhi oleh variabel lain selain stres kerja dan kepuasan kerja yang tidak dijelaskan dalam penelitian ini.

Tabel 2

Koefisien Determinasi

\begin{tabular}{lll}
\hline Model & R & R Square \\
\hline 1 &, $532^{\mathrm{a}}$ &, 283 \\
\hline
\end{tabular}

Sumber: Data Diolah.

Tabel 3 menunjukkan hasil apakah hubungan kedua variabel independen dan dependen memiliki signifikan secara simultan. Dapat dilihat bahwa nilai signifikansi $0,00<0,05$ maka dapat dikatakan bahwa hubungan stres kerja dan kepuasan kerja dengan kinerja karyawan signifikan dan diperoleh $\mathrm{F}_{\text {hitung }}>\mathrm{F}_{\text {tabel }}$ sebesar $36.895>$ 3,04. Hal tersebut dapat dikatakan $\mathrm{H}_{0}$ ditolak dan $\mathrm{H}_{1}$ diterima. Artinya bahwa stres kerja dan kepuasan kerja secara simultan berpengaruh signifikan terhadap kinerja karyawan. 
Tabel 3: Uji Signifikansi Simultan (Uji F)

\begin{tabular}{llccccc}
\hline Model & & $\begin{array}{c}\text { Sum of } \\
\text { Squares }\end{array}$ & df & $\begin{array}{c}\text { Mean } \\
\text { Square }\end{array}$ & F & Sig. \\
\hline 1 & Regression & 3727.762 & 2 & 1863.881 & 36.895 & $.000^{\mathrm{b}}$ \\
& Residual & 9446.910 & 187 & 50.518 & & \\
& Total & 13174.671 & 189 & & & \\
\hline
\end{tabular}

Sumber: Data Diolah.

Tabel 4 menunjukkan hasil apakah hubungan kedua variabel independen dan dependen memiliki signifikansi secara parsial. Jika nilai Sig. $<0.05$ dapat dikatakan bahwa hubungan stres kerja dan kepuasan kerja dengan kinerja karyawan signifikan dan jika nilai $t_{\text {hitung }}>\mathrm{t}_{\text {tabel }}$ atau $-\mathrm{t}_{\text {hitung }}<-\mathrm{t}_{\text {tabel }} \mathrm{H}_{0}$ ditolak dan $\mathrm{H}_{1}$ diterima. Pada Tabel 4 dapat dilihat bahwa pengaruh stres kerja terhadap kinerja karyawan didapat nilai thitung sebesar 6.245 dan diketahui $t_{\text {tabel }}-1,972$ dengan nilai signifikansi 0,000 . Sehingga dapat diambil keputusan $\mathrm{H}_{0}$ ditolak

Pada Tabel 4 dapat dilihat bahwa pengaruh kepuasan kerja terhadap kinerja karyawan didapat nilai $t_{\text {hitung }}$ sebesar 4.943 dan diketahui $t_{\text {tabel }}$ 1,972 dengan nilai signifikansi 0,000. Sehingga dapat diambil keputusan $\mathrm{H}_{0}$ ditolak dan $\mathrm{H}_{1}$ diterima, maka dari itu kepuasan kerja berpengaruh signifikan terhadap kinerja karyawan.

Tabel 4: Hasil Koefisien Regresi

\begin{tabular}{|l|r|r|r|r|r|}
\hline Model & \multicolumn{2}{|c|}{$\begin{array}{c}\text { Unstandardized } \\
\text { Coefficients }\end{array}$} & $\begin{array}{c}\text { Standardized } \\
\text { Coefficients }\end{array}$ & \multirow{2}{*}{ Sig. } \\
\cline { 2 - 4 } & \multicolumn{1}{|c|}{ B } & Std. Error & \multicolumn{1}{c|}{ Beta } & & \\
\hline (Constant) & 71.092 & 4.913 & & 14.470 & .000 \\
Stress Kerja & -.640 & .103 & -.391 & -6.245 & .000 \\
Kepuasan Kerja & .379 & .077 & .309 & 4.943 & .000 \\
\hline
\end{tabular}

Sumber: Data Diolah.

Hasil analisis jalur akan mengukur pengaruh langsung dan tidak langsung dari setiap variabel independen dengan variabel dependen. Tabel 5 menyajikan hubungan langsung dan tidak langsung tersebut. Berdasarkan tabel tersebut nampak bahwa pengaruh total yang diperoleh, 0.283 tidak berbeda dengan nilai $\mathrm{R}^{2}$ pada Tabel 2. Stres kerja dan kepuasan kerja memiliki pengaruh terhadap kinerja karyawan. Nilai 0.283 atau $28.3 \%$ memperlihatkan pengaruh kedua variabel ini relatif tidak terlalu kuat (di bawah 50\%).

Tabel 5: Pengaruh Langsung dan Tidak Langsung

\begin{tabular}{|l|l|l|l|l|l|}
\hline Variabel & \multirow{2}{*}{$\begin{array}{l}\text { Koefisien } \\
\text { Jalur }\end{array}$} & \multicolumn{3}{|c|}{ Kontribusi } & Kontribusi \\
\cline { 3 - 5 } & & Langsung & $\begin{array}{l}\text { Tidak } \\
\text { Langsung }\end{array}$ & Total & \\
\hline $\mathrm{X}_{1}$ & $-0,391$ & $-0,391$ & - & $15,2 \%$ & \\
\hline $\mathrm{X}_{2}$ & 0,309 & 0,309 & - & $9,5 \%$ & \\
\hline $\mathrm{X}_{1}$ dan $\mathrm{X}_{2}$ & & & & & $28.3 \%$ \\
\hline
\end{tabular}

Sumber: Data Diolah. 
Berdasarkan hasil penelitian yang telah dilakukan menyimpulkan bahwa stres kerja berpengaruh signfikan negatif terhadap kinerja karyawan dan kepuasan kerja berpengaruh signifikan positif terhadap kinerja karyawan Telkom Witel Jakarta Utara. Hal ini mendukung temuan dari beberapa penelitian terdahulu

\section{Kesimpulan}

\section{KESIMPULAN DAN SARAN}

Stres kerja karyawan pada perusahaan Telkom Witel Jakarta Utara masuk dalam kategori rendah. Hasil ini dapat dilihat melalui hasil tanggapan responden mengenai stres kerja karyawan terhadap pekerjaannya. Akan tetapi perusahaan Telkom Witel Jakarta Utara tetap perlu mengelola stres kerja karyawan dengan baik agar tidak ada hambatan dalam pekerjaan yang dilakukan karyawan dan berdampak pada hal lainnya.

Kepuasan kerja karyawan perusahaan Telkom Witel Jakarta Utara berdasarkan hasil penelitian yang telah ditunjukkan tergolong dalam klasifikasi sangat tinggi. Hal tersebut dikarenakan perusahaan telah memenuhi, memberikan hak dan kebutuhan karyawan sesuai dengan yang dibutuhkan karyawan dan sesuai dengan peraturan yang telah ditetapkan oleh pemerintah.

Kinerja Karyawan perusahaan Telkom Witel Jakarta Utara berdasarkan hasil penelitian yang telah ditunjukkan tergolong dalam klasifikasi sangat tinggi. Hal tersebut disebabkan perusahaan telah menetapkan standar kerja yang dapat di capai oleh karyawan Telkom Witel Jakarta Utara untuk dapat mendorong perusahaan dalam keberhasilannya.

Hasil yang diperoleh dalam penelitian ini adalah stres kerja berpengaruh signifikan negatif terhadap kinerja karyawan dan kepuasan kerja berpengaruh signifikan positif terhadap kinerja karyawan Telkom Witel Jakarta Utara. Perolehan hasil koefisien determinasi adalah stres kerja dan kepuasan kerja memiliki pengaruh sebesar 28,3\% terhadap kinerja karyawan, sedangkan $71,7 \%$ dipengaruhi oleh variabel lain yang tidak dijelaskan pada penelitian ini

\section{Saran}

Berdasarkan pembahasan pada hasil penelitian ini, penulis memberikan beberapa saran terkait stres kerja dan kepuasan kerja karyawan terhadap kinerja karyawan Telkom Witel Jakarta Utara. Harapannya saran yang diberikan oleh penulis dapat dipertimbangkan untuk kedepannya oleh berbagai pihak, khususnya untuk pihak perusahaan dan pihak akademis. Perusahaan Telkom Witel Jakarta Utara hendaknya memberikan perhatian lebih khusus untuk menambah gaji para karyawan yang memiliki beban pekerjaan yang berat. Hal tersebut dilakukan agar para karyawan memperoleh keadilan dalam mendapatkan gaji yang sesuai dengan beban pekerjaan yang diterima. Ketika karyawan merasa puas dengan pemberian gaji yang diberika oleh perusahaan Telkom Witel Jakarta Utara maka para karyawan akan mempunyai semangat bekerja yang tinggi dan dapat mendorong suatu keberhasilan perusahaan

Pentingnya perusahaan memerhatikan timbal balik yang layak dan adil terhadap karyawannya secara merata dengan cara memberikan fasilitas konsultasi dalam manajemen keuangan agar para karyawan dapat memperoleh kepastian kompensasi untuk masa depan. Selain itu perusahaan Telkom Witel Jakarta Utara hendaknya lebih memotivasi agar para karyawan berlomba-lomba meningkatkan karier untuk mendapatkan kompensasi yang lebih terjamin, sehingga dapat memicu produktivitas kerja karyawan 
Perusahaan Telkom Witel Jakarta Utara penting dalam memberikan kesempatan yang lebih bagi karyawan yang sudah lama bekerja untuk mendapatkan promosi atau bentuk pengembangan karier lainnya. Tujuannya agar menjadi pemacu semangat kerja karyawan dan meningkatkan kepuasan kerjanya. Oleh karena itu, kesempatan promosi harus menjadi pertimbangan perusahaan Telkom Wilte Jakarta Utara untuk menciptakan loyalitas dalam diri karyawan

Perusahaan Telkom Witel Jakarta Utara hendaknya memberi kesempatan untuk karyawan dapat melakukan pekerjaan yang baru dan bervariasi. Hal tersebut dapat dilakukan dengan cara mutasi rutin untuk para karyawan. Bertujuan untuk karyawan mendapat pelajaran dan tantangan baru yang dapat menambah kemampuannya sehingga para karyawan lebih termotivasi lagi dalam bekerja.

Kinerja karyawan pada perusahaan Telkom Witel Jakarta Utara sudah memperoleh hasil yang cukup baik. Hal ini perusahaan seharusnya memberikan penghargaan kepada karyawan atas pencapaiannya seperti pemberian intensif, promosi dan liburan kepada karyawan. Karyawan diharapkan menjadi antusias dalam meningkatkan kinerjanya.

\section{DAFTAR REFERENSI}

Dekoulou, P., \& Trivellas, P. (2015). Measuring the Impact of Learning Organization on Job Satisfaction and Individual Performance in Greek Advertising Sector . Procedia Social and Behavioral Sciences, (175)15, 367-375. doi:10.1016/j.sbspro.2015.01.1212

Diamantidis, A. D., \& Chatzoglou, P. (2018). Factors Affecting Employee Perfomance: An Empirical Approach. International Journal of Productivity and Perfomance Management, 72(3), 1-24. doi:10.1108/IJPPM-01-2018-0012

Edison, E., Anwar, Y., \& Komariyah, I. (2016). Manajemen Sumber Daya Manusia. Bandung: Alfabeta.

Fahmi, I. (2013). Perilaku Organisasi Teori Dan Kasus. Bandung: Alfabeta.

Fahmi, I. (2016). Manajemen Sumber Daya Manusia Teori dan Aplikasi. Bandung: Alfabeta.

Falola, H. O., Osibanjo, A. O., \& Ojo, S. I. (2014). Effectiveness of Training and Development on Employees Perfomance and Organisation Competitiveness in the Nigerian Banking Industry. Economic Sciences, 7(56), 1-10. doi:http://webbut.unitbv.ro/BU2014/Series\%20V/BULETIN\%20V\%20PDF/22_F ALOLA\%2029.06-MARE.pdf

Farooqui, M., \& Nagendra, D. (2014). The Impact of Person organization Fit on Job Satisfaction and Perfomance of the Employees. Procedia Economics and Finance, (11)14, 122-129. doi: 10.1016/S2212-5671(14)00182-8

Fattah, H. (2017). Kepuasan Kerja dan Kinerja Pegawai. Yogyakarta: Elmatera.

Gosmawi, I., \& Dsilva, N. R. (2019). Impact of Job Satisfaction and Job Stress on Employees Life in Mumbai Hospitality Sector An Empirical Study Using SEM. Journal of Strategy and Management, (12)3, 330-346. doi:10.1108/JSMA-012019-0012

Griffin, R. W., \& Moorhead, G. (2013). Organizational Behavior Managing People and Organizations . South-Western: Michael Schenk.

Guinot, J., Chiva, R., \& Roca Puig, V. (2014). Interpersonal Trust, Stress and Satisfaction at Work: an Empirical Study. Personnel Review, (43)1, 96-115. doi: 10.1108/PR-02-2012-0043 
Hanafi, A., Zunaidah, \& Ulfa, M. (2018). The Effect of Job Stress Toward Employee Perfomance Through Job Satisfaction of PT Muara Alam Sejahtera Employees. International Journal of Scientific and Research Publications, (8)8, 1-5. doi:10.29322/IJSRP.8.8.2018.p8002

Hoboubi, N., Choobineh, A., Ghanavati, F. K., Keshavarzi, S., \& Hosseini, A. A. (2017) The Impact of Job Stress and Job Satisfaction on Workforce Productivity in an Iranian Petrochemical Industry. Occupational Safety and Health Research Institute, (8)1, 67-71. doi:10.1016/j.shaw.2016.07.002

Hur, W.-M., Han, S.-J., Yoo, J.-J., \& Moon, T. W. (2015). The Moderating Role of Perceived Organizational Support on The Relationship Between Emotional Labor and Job-Related Outcomes. International Journal of Management Decision, (53)3, 605-624. doi: 10.1108/MD-07-2013-0379

Kasmir. (2016). Manajemen Sumber Daya Manusia Teori dan Praktik. Jakarta: Rajagrafindo Persada.

Khuong, M. N., \& Yen, V. H. (2016). Investigate the Effects of Job Stress on Employee Job Perfomance- A Case Study at Dong Xuyen Industrial. International Journal of Trade, Economic and Finance, (7)2, 1-7. doi:10.18178/ijtef.2016.7.2.495

Luthans, F. (2015). Organizational Behavior. Americas: McGraw-Hill.

Malik, P. (2019, September 18). The Essential Human Resources Problem To Be Solved. https://www.forbes.com/sites/forbeshumanresourcescouncil/2019/09/18/theessential-human-resources-problem-to-be-solved, pp. 1-3.

Mangkunegara, A. P. (2013). Manajemen Sumber Daya Manusia Perusahaan. Bandung: PT Remaja Rosdakarya.

Masram, \& Mu'ah. (2017). Manajemen Sumber Daya Manusia Profesional. Sidoarjo: Zifatama Publisher.

Melian Gonzalez, S., \& Bulchand Gidumal, J. (2015). New Evidence of the Relationship Between Employee Satisfaction and Firm Economic Perfomance. Personal Review, (44)6, 906-929. doi:10.1108/PR-01-2014-0023

Millin, D. (2019, September 18). Innovation: How To Find (And Keep) Your Competitive Edge. https://www.forbes.com/sites/forbesbostoncouncil/2019/09/18/innovation-how-tofind-and-keep-your-competitive-edge, pp. 1-2.

Nyangahu, K. P., \& Bula, H. O. (2015). Relationship Between Work Stress and Perfomance of Employees: A Case Study of Transit Hotel in Nairobi City Country. Archieves of Business Research, (3)6, 1-16. doi:10.14738/abr.36.1538.

Pang, K., \& Lu, C. (2018). Organizational Motivation,Employee Job Satisfaction and Organizational Perfomance. Maritime Business Review, (3)1, 1-18. doi:10.1108/MABR-03-2018-0007

Pradhan, R. K., \& Jena, L. K. (2017). Employee Performance at Workplace: Conceptual Model and Empirical Validation. Business Perspective and Research, 69-85. doi:10.1177/2278533716671630

Prasetio, A. P., Luturlean, B. S., \& Agathanisa, C. (2019). Examining Employee's Compensation Satisfaction and Work Stress in A Retail Company and Its Effect to Increase Employee Job Satisfaction. International Journal of Human Resource Studies, 9(2), 239-265. doi:10.5296/ijhrs.v9i2.14791

Rajeshwaran, M. R., \& Aktharsha, D. S. (2017). Job Stress, Job Perfomance and Job Satisfaction. Journal of Business and Management , 8(19), 71-80. doi: 10.9790/487X-1908017180

Riduwan, \& Kuncoro, E. A. (2017). Path Analysis ( Analisis Jalur). Bandung: Alfabeta. 
Robbins, S. P., \& Judge, T. A. (2018). Essentials of Organizational Behavior. United States: Pearson Education.

Shafiq, S., \& Hamza, S. M. (2017). The Effect of Training and Development on Employee Perfomance in Private Company. International Journal of Education Learning and Training , 2(2), 42-56. doi:DOI: 24924/ijelt/2017.04/v2.iss2/42.56

Singh, R., \& Nayak, J. K. (2015). Mediating Role of Stress Between work Family Conflict and Job Satisfaction Among The Police Officials. International Journal of Police Strategies \& Management, (38)4, 1-26. doi:10.1108/PIJPSM-03-2015-0040

Valaei, N., \& Jiroudi, S. (2016). Job Satisfaction and Job Perfomance in The Media Industry. Asia Pacific Journal of Marketing and Logistics, (28)5, 984-1014. doi:10.1108/APJML-10-2015-0160 